\title{
Dilma Rousseff e José Serra em CartaCapital e Veja: uma análise dos enquadramentos dos (pré) candidatos à presidência em 2010
}

\author{
Milena Boemo JAENiSCH \\ Universidade Federal de Santa Maria - miboemo@yahoo.com.br \\ Graduada em Comunicação Social - Jornalismo \\ VIVIANE BORELLI \\ Universidade Federal de Santa Maria - viviborelli10@gmail.com \\ Professora do Departamento de Ciências da Comunicação
}

\begin{abstract}
Resumo
Este trabalho apresenta uma análise dos diferentes enquadramentos apresentados pelas revistas CartaCapital e Veja dos pré-candidatos à Presidência da República Dilma Rousseff (PT) e José Serra (PSDB) no período pré-eleitoral de 2010. Assim, objetiva mostrar os posicionamentos editoriais dos semanários, de forma a trazer questionamentos acerca da existência dos pressupostos de objetividade e imparcialidade jornalísticos. Após a prévia leitura do material veiculado sobre Dilma e Serra, foram escolhidas as edições nas quais as marcas de posicionamento eram mais evidentes. Por meio de análises qualitativas e quantitativas de adjetivações e títulos foi realizada uma comparação entre os dados e dessa forma, o posicionamento editorial foi visualizado na construção da imagem dos presidenciáveis. CartaCapital construiu José Serra negativamente, enquanto Veja enquadrou Dilma Rousseff de forma negativa.
\end{abstract}

\section{Palavras-chave}

Enquadramento, eleição presidencial de 2010, posicionamento editorial.

\begin{abstract}
This paper presents an analysis of the different framing presented by magazines CartaCapital and Veja of the pre-candidates for president Dilma Rousseff (PT) and Jose Serra (PSDB) in the pre-election period of 2010. Thus, the objective is showing the positions of editorial weeklies, to raise questions about the existence of conditions of journalistic objectivity and impartiality. After the preliminary reading of the material aired on Dilma and Serra were selected issues on which brands were most obvious position. Through qualitative and quantitative analysis of adjectives and titles was performed to compare the data and then the editorial position was displayed in the image building of the presidential candidates. CartaCapital builds José Serra negatively, while Veja framed Dilma Rousseff negatively.
\end{abstract}

Keywords

Framing, presidential election of 2010 , editorial position.

Artigo recebido em 19/04/2011 Aprovado em 29/04/2011 
s interações entre a comunicação e a política, sejam elas de
complementaridade ou de conflito, são potencializadas em anos eleitorais e
observadas pelos diferentes enquadramentos nos veículos. O presente artigo se propõe a analisar as diferenças de enquadramentos dos pré-candidatos à Presidência da República em 2010 Dilma Rousseff (PT) e José Serra (PSDB) no período préeleitoral pelas revistas semanais informativas brasileiras CartaCapital (CC) e Veja. A escolha destes semanários se dá devido às diferentes posturas editoriais assumidas pelos veículos.

A análise se limita à Dilma Rousseff e a José Serra, pois diversas pesquisas os trouxeram como os principais concorrentes ao cargo máximo do Executivo, tendo em vista que eram apontados como os detentores dos maiores índices de intenções de voto. Deve-se lembrar que dentre os nove pré-candidatos à Presidência, Marina Silva (PV) também foi bastante citada nas pesquisas, porém com índices menores, havendo uma polarização entre o pré-candidato do PSDB e a do PT. A escolha pelo período préeleitoral se dá devido à inexistência de um número significativo de pesquisas que explorem esse espaço de tempo, o qual também faz parte do processo do pleito. Com a proximidade das eleições, os posicionamentos se acentuam cada vez mais, mas eles já podem ser percebidos desde as primeiras publicações dos veículos em questão.

Também se faz necessário o entendimento da notícia como uma construção da realidade e o questionamento dos pressupostos de objetividade e imparcialidade jornalísticos. Para isso, utiliza-se a teoria construtivista da notícia (TRAQUINA, 1993) e Alsina (2009) e os conceitos de agendamento (McCOMBS e SHAW, 1972 apud TRAQUINA, 2001) e de enquadramento (GOFFMAN, 1975 apud TUCHMAN, 1993), para que a questão ideológica, que permeia os meios de comunicação e mais diretamente as empresas de comunicação, seja explorada.

O embate político é alimentado pelas possíveis interpretações da realidade, envolvendo a montagem e a seleção de alguns aspectos em prol de outros. Portanto, a escolha pelo estudo comparativo das revistas CartaCapital e Veja possibilita a compreensão do processo de construção das imagens públicas de Dilma Rousseff e José Serra, evidenciando que os veículos assumem posições editoriais opostas. Diante disso, 
a questão central é identificar em que medida os modos de construção dos précandidatos apontam para tomadas de posturas singulares por parte dos semanários.

\section{A construção da realidade: espelho quebrado}

O jornalismo suscita muitos questionamentos acerca dos processos que envolvem a constituição das notícias. Na tentativa de encontrar explicações, existem inúmeras teorias que tentam elucidar os motivos pelos quais as notícias são como são, de formas complementares e por vezes controversas.

A teoria pioneira que visou a esclarecer o processo noticioso foi a teoria do espelho, oferecida pela própria ideologia dominante do campo jornalístico nos países ocidentais. Ela conceitua as notícias como sendo espelhos da realidade, determinadas pela mesma. A noção-chave é a de que o jornalista é um "comunicador desinteressado" (TRAQUINA, 2001), ou ainda, um "agente que não tem interesses específicos a defender e que o desviam da sua missão de informar, procurar a verdade, contar o que aconteceu, doa a quem doer" (TRAQUINA, 2001, p.65).

Após a mudança de paradigma, no século XIX, com um novo jornalismo - o jornalismo de informação - (TRAQUINA, 2001), houve a separação entre fatos e opiniões. A notícia deixa de ser associada às opiniões e passa a ser identificada com os fatos. Assim, o papel do jornalista foi definido como o de observador que relata com equilíbrio e honestidade o que acontece, sendo imprescindível o cuidado para não emitir relatos pessoais. Essa concepção ainda domina o campo jornalístico ocidental.

Também o surgimento do conceito de objetividade, nos anos 20 e 30, nos EUA, reforçou a constituição de uma identidade ao profissional da comunicação (ethos), confirmada com procedimentos e regras, "com a ideologia da objetividade, os jornalistas substituíram uma fé simples nos fatos por uma fidelidade às regras e procedimentos criados para um mundo no qual até os fatos eram postos em dúvida" (SCHUDSON, 1978, p.122 apud TRAQUINA, 2001, p.67).

Assim, é criado um ethos jornalístico (TRAQUINA, 2004), relacionado aos pressupostos de objetividade e imparcialidade, o qual abrange valores e normas que identificam o jornalista com um papel de árbitro, além de procedimentos identificados 
com o profissionalismo que confirmam a legitimidade e a credibilidade da profissão.

Todavia, as pesquisas na década de 1970 constituem um momento de mudança de pensamento, sendo as notícias vistas então como uma construção social da realidade. O ponto principal de discordância das duas teorias reside na posição tomada em relação à ideologia jornalística. Nos estudos que utilizam as notícias como construção, a teoria do espelho é amplamente rejeitada. Entre as razões dessa negação por parte dos pesquisadores, está a impossibilidade de estabelecer uma distinção radical entre a realidade e as mídias noticiosas "que devem refletir essa realidade porque as notícias ajudam a construir a própria realidade" (TRAQUINA, 2001, p.60).

As notícias devem ser interpretadas como o resultado de acordos - implícitos e explícitos - entre os agentes das redes. Como as redes profissionais são entremeadas com estabelecimentos políticos e sociais, as notícias "aparecem como o desafio de estratégias nas quais intervêm (segundo termos de Maloch e Lester) "promotores", "montadores" do acontecimento" (MOUILLAUD, 2002, p. 55). Dessa forma, a teoria do espelho torna-se uma explicação pobre e insuficiente, sendo necessária uma nova concepção que vá além da visão limitada da notícia como reflexo da realidade observada. O complexo processo de produção noticiosa reúne rotinas e práticas que se constituem como centrais na teoria construtivista dos anos 70. "As rotinas de produção englobam e são constitutivas da ideologia" (SCHLESINGER, 1980, p.3673 apud TRAQUINA, 2001, p.62).

Traquina (1993) defende que os jornalistas não são meros espectadores daquilo que acontece, e sim participantes ativos no processo de construção da realidade. A mídia pode ser vista como criadora da realidade social, os acontecimentos chegam até o público por meio dela e são construídos através da sua realidade discursiva. Esse modelo trata a mídia como geradora da realidade social (VERÓN, 1981 apud ALSINA, 2009), e assim, o processo de construção da realidade depende completamente da prática produtiva do jornalismo, a qual engloba uma série de influências externas.

Então, pode-se dizer que os jornalistas tem um papel socialmente legitimado e institucionalizado para construir a realidade social como realidade pública e socialmente relevante. Essas competências são realizadas no interior de aparatos de produção específicos: a mídia (ALSINA, 2009, p.47). Além disso, o autor lembra a interação 
daquilo que é veiculado com a respectiva audiência, esclarecendo que a construção da realidade inclui os processos de produção, circulação e reconhecimento das notícias.

\section{Da objetividade à parcialidade: influência ideológica}

Quando se aborda a influência ideológica no jornalismo, faz-se necessário entender dois pressupostos de qualquer cobertura, que são a objetividade e a imparcialidade. Pois, é justamente da falta e/ou do desequilíbrio destes que surge o posicionamento de um veículo ao invés da sua idealizada isenção.

A parcialidade no conteúdo veiculado pelas mídias pode ser detectada por métodos de leitura e provém de atitudes dos jornalistas ou dos executivos editoriais, sendo que "a forma mais importante de parcialidade é o partidarismo" (HACKETT, 1993, p.101). Os conceitos de objetividade e parcialidade são normalmente associados ao papel político e ideológico da imprensa. Grande parte das definições de parcialidade noticiosa a consideram como o ingresso da opinião subjetiva do repórter, ou da organização jornalística da qual ele faz parte, na matéria.

Robert A. Hackett (1993), em um resgate histórico destes conceitos, salienta que a parcialidade noticiosa tem dois momentos que não são inteiramente consistentes, “(...) um é a falta de equilíbrio entre pontos de vista concorrentes; o outro é a distorção tendenciosa e partidária da realidade" (DOLL e BRADLEY, 1974, p.256 apud HACKETT, 1993, p.103).

A relação entre os dois conceitos se dá como causa e efeito, pois a falta de um (objetividade) leva ao outro (parcialidade). O culto à objetividade nasceu no jornalismo nos anos 1920 e 1930, nos EUA, em meio a uma mudança de paradigma nas coberturas midiáticas, que deixava as opiniões e ingressava apenas nos fatos, como já relatado anteriormente. Isso fez com que os jornalistas buscassem métodos e procedimentos que efetivassem a credibilidade daquilo que era noticiado.

A objetividade no jornalismo não é a negação da subjetividade, mas uma série de procedimentos que os membros da comunidade interpretativa utilizam para assegurar uma credibilidade como parte não-interessada e se protegerem contra eventuais críticas ao seu trabalho (TRAQUINA, 2004, p.139). 
Dessa busca de procedimentos legitimadores, surgiu um "ritual estratégico", apresentando por Gaye Tuchman (1993), composto de quatro itens que levam o jornalista a mascarar a sua subjetividade e fazer parecer que é objetivo. O primeiro é a apresentação de possibilidades conflituais, que é a exposição de opiniões contrárias, os "dois lados da questão", sem ter nenhum favorecimento.

O segundo é a apresentação de provas auxiliares. Estas além de confirmar o que é dito, podem dar solidez ao fato, já que ele não fala por si, é dependente de processos sociais. O terceiro é o uso judicioso das aspas. As citações de opiniões de outras pessoas fazem com que a figura do repórter desapareça e apenas aquela voz sinalizada se faça presente. Porém, essa escolha do jornalista visa a parecer que apenas a fonte fala, quando, na realidade, é ele quem elege quem fala e o que deve ser dito.

E o quarto e último procedimento é a estruturação da informação numa sequência apropriada. A informação mais importante relativa a um acontecimento é suposta ser apresentada no primeiro parágrafo, de forma que a estrutura da notícia assemelhe-se a uma pirâmide invertida.

Para que se entenda a conversão de um acontecimento em notícia, deve-se saber que ele primeiramente tem que ser compatível com a estrutura editorial do veículo de comunicação em questão. De acordo com o sociólogo Warren Breed (1955/1993 apud TRAQUINA 2001), o jornalista conforma-se mais com as normas editoriais da política editorial da organização do que com as crenças pessoais que ele possui. O profissional acaba sendo socializado com as normais editoriais, numa relação de recompensa e punição:

(...) a aprendizagem da política editorial é um processo através do qual o novato descobre e interioriza os direitos e obrigações do seu estatuto, bem como as suas normas e valores. Aprende a antever aquilo que se espera dele, a fim de obter recompensas e evitar penalidades (BREED, 1955/1993, p.155 apud TRAQUINA, 2001, p. 72).

Além da compatibilidade com a empresa, também é critério de passagem à categoria de notícia o espaço que o acontecimento virá a ocupar numa página. Para Berger (2002) a noticiabilidade, conjunto de valores-notícia que determinam o que deve 
ser noticiado, é definida pelo espaço ocupado, pela aprovação do anunciante e pela apreciação do leitor, de forma a delimitar a natureza da imprensa. "A questão para um editor é: o que há de novo no mundo de hoje que "caiba" (nos dois sentidos) no meu jornal, que conquiste leitores e não se confronte com os que o sustentam economicamente" (BERGER, 2002, p.274). O termo citado "caiba" refere-se ao espaço e à política editorial, portanto, a uma tomada de posição.

$\mathrm{Na}$ cobertura política, em especial, os interesses de determinados grupos, expressados por favoritismos em relação a candidatos, partidos e posições políticas, confirmam a premissa de que os meios de comunicação assumem posições ideológicas, "A ela (imprensa) cabe, em última instância, organizar discursivamente o mundo como convém a quem o domina" (BERGER, 2002, p.279).

A linguagem neutra, isenta de juízos de valor, sem preconceitos, sem nenhum tipo de influência é impossível, porque as avaliações estão implícitas nos conceitos, na linguagem que engloba observações e registros. Os acontecimentos são contextualizados de acordo com os interesses e posições assumidas, consequência disso são os diferentes enquadramentos observados nas coberturas dos mesmos assuntos.

A análise do favoritismo da imprensa em relação a um candidato, partido ou grupo pode ser mais ampla e articulada como o estabelecimento de quadros do mundo a serviço de uma classe ou do Estado. Esses quadros tendenciosos (ideológicos) levam à noção de enquadramento noticioso, o qual pode ser identificado devido a um agendamento prévio dos assuntos.

\section{Agendamento e enquadramento}

A teoria do agendamento (agenda-setting) foi exposta pela primeira vez em um artigo de uma revista norte-americana (MCCOMBS e SHAW, 1972 apud TRAQUINA, 2001) em 1972. Com o tempo, as investigações modificaram a concepção inicial de que havia uma relação causal entre a agenda midiática e a agenda pública.

Cohen (1963 apud TRAQUINA 2001) avançou no conceito de agendamento e o exemplificou dizendo que a imprensa 
pode, na maior parte das vezes, não conseguir dizer às pessoas como pensar, mas tem, no entanto, uma capacidade espantosa para dizer aos seus próprios leitores sobre o que pensar. O mundo parece diferente a pessoas diferentes, dependendo do mapa que lhes é desenhado pelos redactores, editores e diretores do jornal que lêem (COHEN, 1963, p.72 apud TRAQUINA, 2001, p.18-19) (grifo acrescentado).

Após mais de vinte anos, os precursores dos estudos de agendamento, McCombs e Shaw, escrevem que essa teoria vai além da definição de quais assuntos são pertinentes, pois também engloba as formas pelas quais eles são abordados. Assim, o clássico entendimento de Bernard Cohen (1963 apud TRAQUINA 2001) é modificado.

O agendamento é consideravelmente mais que a clássica asserção que as notícias nos dizem sobre o que pensar. As notícias também nos dizem como pensar nisso. Tanto a seleção de objetos que despertam a atenção como a seleção de enquadramentos para pensar esses objectos são poderosos papéis do agendamento (McCOMBS e SHAW, 1993, p.62 apud TRAQUINA, 2001, p.33) (grifo acrescentado).

Segundo os estudiosos Iyengar, Peters e Kinder (1982/1991 apud TRAQUINA, 2001), a agenda pública é mais facilmente moldada conforme a agenda midiática, do que o inverso. Isso ocorre porque as pessoas que estão expostas às notícias veiculadas identificam-nas como importantes, pelo fato de estarem sendo publicizadas, de forma a definir a agenda pública.

O processo de agendamento pode ser entendido como interativo. De acordo com Ebring, Goldenberg e Miller (1980 apud TRAQUINA, 2001), a influência da agenda pública sobre a agenda jornalística é um processo gradual, através do qual, a longo prazo, os critérios de noticiabilidade são criados. Já a influência da agenda jornalística sobre a agenda pública é direta e imediata, sendo mais facilmente verificável nas questões em que o público não dispõe de conhecimento prévio e necessita de uma orientação, como se pode perceber em períodos (pré) eleitorais.

O importante papel do agendamento que o campo jornalístico possui também determina a agenda de atributos ou qualidades da imagem dos candidatos políticos. A construção da imagem dos candidatos (image agenda-setting) tem um grande poder persuasivo nas decisões do eleitorado. 
Para McCombs (1992 apud TRAQUINA 2001), os atributos enfatizados pelo campo jornalístico em uma cobertura podem influenciar diretamente a direção da opinião pública. Tanto a seleção das ocorrências e/ou questões que constituirão a agenda, como a seleção dos enquadramentos para interpretar essas ocorrências e/ou questões são poderes importantes que o conceito de agendamento identifica depois de mais de vinte anos de vida intelectual. $\mathrm{O}$ autor redescobre o poder do jornalismo por meio da seleção de tópicos e de enquadramentos, "a seleção dos tópicos para a agenda jornalística e a seleção de enquadramentos para as 'estórias' acerca desses tópicos são poderosos papéis de agendamento e responsabilidades éticas terríveis" (McCOMBS, 1922, p. 820-821 apud TRAQUINA, 2001, p. 54).

A agenda de atributos é conceituada como enquadramento (framing), que surgiu junto à teoria do agendamento na década de 1970. Ambos encontram-se no âmbito dos modelos teóricos dos efeitos midiáticos, sendo o enquadramento um herdeiro do agendamento. A metáfora do framing foi utilizada inicialmente em 1974 pelo sociólogo canadense Erving Goffman, para caracterizar de que forma os indivíduos compreendiam e respondiam às situações sociais a partir do modo pelo qual organizavam a vida cotidiana.

O termo foi usado para identificar tipos de categorias, as quais ajudavam na estruturação da experiência diária e facilitavam o processo de construção de sentidos. Robert Entman (1993 apud GUTMANN, 2006) caracteriza o framing como esquemas de processamento de informação, ou ainda, como a construção do conteúdo jornalístico a partir de uma espécie de "embalagem" particular, seleção e ênfase:

\footnotetext{
Enquadrar é selecionar alguns aspectos de uma realidade percebida e fazer eles mais salientes no texto comunicativo de modo a promover uma definição particular de um problema, interpretação causal, avaliação moral e/ou um tratamento recomendado para o item descrito (ENTMAN, 1993, p. 52 apud GUTMANN, 2006, p. 32).
}

De um modo geral, a noção de enquadramento se relaciona "aos ângulos de abordagem dados aos assuntos pautados pelos meios de comunicação" (GUTMANN, 2006, p. 6). O termo designa "moldura", que é construída para os temas e acontecimentos midiáticos, sendo também utilizada na interpretação dos mesmos. "O 
frame ${ }^{i}$ seria justamente o quadro a partir do qual um determinado tema é pautado e, consequentemente, processado e discutido na esfera pública" (GUTMANN, 2006, p. 6).

Maurice Mouillaud (2002) colabora com a questão por meio de conceitos que aplica ao jornal. O autor esclarece que aparentemente a moldura é posterior ao quadro, porém o quadro procede de um enquadramento implícito que o procedeu. Este é composto, entre outros, pelo dispositivo no qual está inserido. Entende-se por dispositivos "as matrizes (muito mais do que suportes) em que se vinham inscrever os textos. Nesse sentido, o dispositivo existe antes do texto (...) comanda sua duração e a extensão" (MOUILLAUD, 2002, p.33). Ele possui uma forma que é sua especificidade, um modo de estruturação no tempo e no espaço.

Mesmo com a existência de dispositivos, o texto não é passivo. "Se o jornal gerou títulos, (...) os títulos "fazem" o jornal" (MOUILLAUD, 2002, p.33). Através do conceito de dispositivo, Mouillaud (2002) defende que ao enquadrar num determinado espaço um texto ou uma imagem, o jornal está predeterminando os sentidos.

Para identificar o enquadramento de uma reportagem, Entman (1993 apud GUTMANN, 2006) apresenta cinco elementos que devem ser observados: palavraschave, metáforas, conceitos, símbolos e imagens enfatizadas na narrativa jornalística. Isto significa que o enquadramento pode ser identificado através da observação de imagens visuais e palavras repetidas insistentemente em um texto midiático para tornar algumas ideias mais aparentes que outras.

No que se refere à cobertura eleitoral, a mídia define uma agenda de atributos para cada candidato e os eleitores, a partir dessa exposição e do contato com outras fontes, constroem uma imagem do mesmo.

\section{Análise dos enquadramentos em CartaCapital e Veja}

A pesquisa comparativa entre os semanários CartaCapital e Veja foi realizada durante o período pré-eleitoral de 2010: de $1^{\circ}$ de janeiro até o dia 2 de julho. A metodologia foi construída a partir da análise de enquadramento (SOARES, 2009) e de algumas técnicas da análise de conteúdo (BARDIN, 1988 apud FONSECA JÚNIOR, 2009). A análise de conteúdo (AC) surgiu no século XVIII nas diversas áreas de 
conhecimento: ciências políticas, psicologia, sociologia, crítica literária e comunicação de massa. A clássica conceitualização de análise de conteúdo, datada de 1952, citada por autores como Kientz (1973), Bardin (1988) e Krippendorff (1990), entende-a como "uma técnica de pesquisa para a descrição objetiva, sistemática e quantitativa do conteúdo manifesto da comunicação". Krippendorff (1990, p.29 apud FONSECA JÚNIOR, 2009, p.284) defende que é a técnica "destinada a formular, a partir de certos dados, inferências reproduzíveis e válidas que podem se aplicar a seu contexto".

A análise de conteúdo é considerada uma técnica híbrida, tendo em vista o fato de que oscila entre os pólos quantitativo e qualitativo, dependendo da ideologia e dos interesses do pesquisador. A análise de enquadramento também se ocupa dos aspectos relativos à quantidade e à qualidade do que é veiculado, aproximando-se assim da AC. Tendo em vista a existência de semelhanças entre as técnicas de análise de conteúdo e de enquadramento, a metodologia abrangeu essas similitudes.

No período pré-eleitoral foram publicadas 51 edições, 25 de CartaCapital e 26 de Veja. As que compõem o corpus somam quatro edições: duas de CartaCapital, datadas de 10/02/10 (edição ${ }^{\text {ii }} n^{\circ} 582$ ) e 10/03/10 ( edição $n^{\circ} 586$ ) e duas de Veja, datadas de 27/01/10 (edição $n^{o} 2149$ ) e 24/02/10 (edição ${ }^{i i i} n^{o} 2153$ ). Estas foram selecionadas devido ao fato de apresentarem matérias que trazem os pré-candidatos de forma principal e não como assunto secundário na sua composição. Além disso, trazem apontamentos concretos sobre o posicionamento dos veículos, que são explicitados nas adjetivações.

Dentro do jornalismo informativo, são analisados os gêneros notícia, reportagem e entrevista, considerando já a reportagem de revista, como explica Pena (2005), integrante da categoria jornalismo interpretativo. A chamada reportagem polêmica (PENA, 2005), que pode ser relacionada à cobertura pré-eleitoral, explora o assunto ao ouvir fontes e especialistas que pensem de modo diferenciado.

As colunas assinadas não fazem parte da coleta, já que elas mantêm uma posição mais fortemente determinada pelos seus autores e não explicitariam o objetivo do trabalho, que é o de verificar o posicionamento de cada veículo como um todo e não de um de seus colunistas em específico. As seções clássicas de jornalismo opinativo, conhecidas como Editorial, Carta ao Leitor, ou assemelhados, também não integraram 
a coleta, porque o trabalho se propõe a analisar a existência ou não de um posicionamento das revistas nas matérias informativas e não nestes espaços, que existem justamente para expressar o posicionamento das empresas jornalísticas.

Tendo em vista que a notícia é um processo complexo e construído a partir de vários procedimentos jornalísticos, foram escolhidas as matérias de cunho informativo, ou referencial, que é a essência da notícia, como afirma Nilson Lage (1985), “A retórica da notícia é referencial, por definição" (LAGE, 1985, p.25).

Tem-se como categoria de análise a adjetivação, que engloba as adjetivações relacionadas aos nomes Dilma Rousseff e José Serra. Entende-se por adjetivo “a palavra invariável que modifica o substantivo, indiciando-lhe uma qualidade, um estado ou um modo de ser" (CAMPEDELLI e SOUZA, 1999, p.104). Segundo os autores, existem também as locuções adjetivas, que resultam da união de duas ou mais palavras com função de adjetivo. Normalmente são formadas por uma preposição e um substantivo ou por uma preposição e um advérbio.

As adjetivações foram separadas em positivas e negativas, permitindo a contagem dos dados coletados. Eles evidenciarão a existência de um posicionamento por parte de cada uma das revistas e o consequente enquadramento. Também foi abordada a hierarquização editorial, pois é crucial ao estudo o reconhecimento de que uma adjetivação em uma manchete torna-se mais visível do que no corpo de texto.

Então, usa-se M para manchete, CP para chamada de capa, TP para título da matéria principal, ST para subtítulo, L para legenda, CT para corpo de texto e D para destaque. Inicia-se com as tabelas referentes ao semanário CartaCapital: 
TABELA 1 - Adjetivações em CartaCapital edição n ${ }^{\circ} 582$ de 10/02/10

\begin{tabular}{|c|c|}
\hline DILMA ROUSSEFF & JOSÉ SERRA \\
\hline $\begin{array}{l}\text { Dilma cresce e pode liderar as pesquisas em } \\
\text { breve }-\mathrm{CP}\end{array}$ & $\begin{array}{l}\text { Serra diz esperar o momento certo para se } \\
\text { candidatar, mas corre o risco de decidir na hora } \\
\text { errada }-\mathrm{CP}\end{array}$ \\
\hline $\begin{array}{l}\text { Não que o crescimento nas pesquisas da ministra } \\
\text { Dilma Rousseff, turbinada pela popularidade do } \\
\text { presidente Lula, fosse inesperado (p.20)-CT }\end{array}$ & $\begin{array}{l}\text { O governador José Serra (...) vê sua margem de } \\
\text { manobra reduzida }(\ldots)(\text { p.20) - ST }\end{array}$ \\
\hline $\begin{array}{l}\text { (...) Dilma, o "poste" a quem muitos analistas } \\
\text { vaticinavam não chegar a } 20 \% \text { quando seu nome } \\
\text { surgiu na parada, subiu de } \mathbf{3 \%}(\ldots) \text { para } 27,8 \% \\
\text { nas intenções de voto agora }(\text { p. } 21)-\text { CT }\end{array}$ & $\begin{array}{l}\text { Disposto a controlar todas as variáveis do cenário } \\
\text { eleitoral antes de entrar em campo, o tucano não } \\
\text { contava com o efeito sobre o eleitorado da sua } \\
\text { indecisão e da determinação clara do bloco } \\
\text { governista em enraizar a candidatura da ministra. } \\
\text { (p.20) - CT }\end{array}$ \\
\hline $\begin{array}{l}\text { (..) a ascensão da ministra entre o público } \\
\text { masculino mostra a consolidação de um } \\
\text { movimento político em torno de sua candidatura } \\
\text { (p.21)-CT }\end{array}$ & $\begin{array}{l}\text { Em uma análise fria dos números, Serra não } \\
\text { despencou nas pesquisas: caiu de } \mathbf{4 0} \% \text { para } \mathbf{3 3 \%} \text {, } \\
\text { de acordo com o Sensus (p. } 21)-\mathrm{CT}\end{array}$ \\
\hline $\begin{array}{l}\text { Momentos. Impulsionada por Lula, Dilma cresce. } \\
\text { (p.21) - L }\end{array}$ & $\begin{array}{l}\text { (...) e não é de hoje, a candidatura de Serra está } \\
\text { estagnada, ao menos nas pesquisas (p.21) - CT }\end{array}$ \\
\hline \multirow[t]{5}{*}{$\begin{array}{l}\text { (...) ameaçadora ascensão de Dilma Rousseff nas } \\
\text { pesquisas (...)(p.20)-ST }\end{array}$} & $\begin{array}{l}\text { O clima em São Paulo tem literalmente embaçado } \\
\text { a imagem eleitoral do governador (p.21) - CT }\end{array}$ \\
\hline & $\begin{array}{l}\text { Como desempacar Serra é o tema principal no } \\
\text { QG tucano (p.21) - CT }\end{array}$ \\
\hline & $\begin{array}{l}\text { A ideia é convencer o eleitor de que Serra teria } \\
\text { demonstrado, como ministro, prefeito e governador } \\
\text { de São Paulo, sua competência como } \\
\text { administrador. (p.22)-CT }\end{array}$ \\
\hline & $\begin{array}{l}\text { (...) avalia-se que reforçaria a imagem de } \\
\text { governador "que trabalha" e não abandona o } \\
\text { estado em meio a catástrofes provocadas por } \\
\text { eventuais enchentes. (p.23)-CT }\end{array}$ \\
\hline & (...) Serra está estagnado. (p.21) - L \\
\hline
\end{tabular}

TABELA 2 - Adjetivações em CartaCapital edição no 586 de 10/03/10

\begin{tabular}{|c|c|}
\hline DILMA ROUSSEFF & JOSÉ SERRA \\
\hline (...) Dilma Rousseff cresce (p.40)-CT & $\begin{array}{l}\text { (...) a queda de Serra se deu no mês em que FHC } \\
\text { decidiu topar o desafio sonhado por Lula (p.24) - } \\
\text { CT }\end{array}$ \\
\hline \multirow[t]{7}{*}{ Dilma cresce nas pesquisas (...), (p.41) - L } & $\begin{array}{l}\text { (...) o governador paulista continua firme na sua } \\
\text { criticada estratégia (p.40) - ST }\end{array}$ \\
\hline & (...) esnobado por Aécio Neves (p.40) - CT \\
\hline & Está em quedas nas pesquisas (...) (p.40)-CT \\
\hline & $\begin{array}{l}\text { (...) uma candidatura que vem, nas últimas } \\
\text { pesquisas, deslizando serra a baixo (p.41) }- \text { CT }\end{array}$ \\
\hline & $\begin{array}{l}\text { O governador paulista detem o controle da } \\
\text { campanha com mãos de ferro e se mostra seguro } \\
\text { nas decisões que toma (p.41)-CT }\end{array}$ \\
\hline & $\begin{array}{l}\text { (...) sonega informação dos próprios companheiros } \\
\text { de legenda (p.41) - CT }\end{array}$ \\
\hline & $\begin{array}{l}\text { (...) enquanto Serra irrita-se com o convite de } \\
\text { Aécio a Lula (p.41)-L }\end{array}$ \\
\hline
\end{tabular}


A revista Veja também trouxe adjetivações, conforme as tabelas a seguir:

TABELA 3 - Adjetivações em Veja edição no 2149 de 27/01/10

\begin{tabular}{|l|l|}
\hline \multicolumn{1}{|c|}{ DILMA ROUSSEFF } & \multicolumn{1}{|c|}{ JOSÉ SERRA } \\
\hline $\begin{array}{l}\text { O presidente do PSDB (...) disse que Dilma } \\
\text { Rousseff é "mentirosa" (p.56) - ST }\end{array}$ & $\begin{array}{l}\text { O presidente do PT, Ricardo Berzonini, } \\
\text { respondeu, chamando de (...) "hipócrita” o } \\
\text { governador de São Paulo (p.57) - CT }\end{array}$ \\
\hline $\begin{array}{l}\text { Foi chamada de mentirosa em uma nota oficial do } \\
\text { PSDB (p.57) - CT }\end{array}$ & \\
\hline inexperiente na disputa eleitoral (p.57) - CT & \\
\hline Sem traquejo político (p.57) - CT & \\
\hline Foi uma invenção do presidente (p.57) - CT & \\
\hline Sem experiência política (p.58) - CT & \\
\hline $\begin{array}{l}\text { Com temperamento forte e explosivo (p.58) - } \\
\text { CT }\end{array}$ & \\
\hline $\begin{array}{l}\text { (...) Dilma é conhecida por reações muito mais } \\
\text { intempestivas que essa (p.58) CT }\end{array}$ & \\
\hline
\end{tabular}

TABELA 4 - Adjetivações em Veja edição n 2153 de 24/02/10

\begin{tabular}{|l|l|}
\hline \multicolumn{1}{|c|}{ DILMA ROUSSEFF } & \multicolumn{1}{|c|}{ JOSÉ SERRA } \\
\hline $\begin{array}{l}\text { A frase merece o comentário que Dilma mais } \\
\text { aprecia: “A senhora tem razão!” (p.52) - CT }\end{array}$ & $\begin{array}{l}\text { A frieza do governador (...) deixa à beira do infarto } \\
\text { a maior parte de seus aliados (p.60) - CT }\end{array}$ \\
\hline $\begin{array}{l}\text { Sem nunca ter enfrentado nem eleição de } \\
\text { condomínio, ela vai buscar votos (p.52) - CT }\end{array}$ & $\begin{array}{l}\text { "Nervos de aço" - O tucano diz que a } \\
\text { movimentação do PT em torno de Dilma não o fará } \\
\text { mudar seus planos (p.60) - L }\end{array}$ \\
\hline $\begin{array}{l}\text { Organizada e centralizadora, ela vai se deixar } \\
\text { levar caoticamente por uma caravana eleitoral } \\
\text { que exige (...) (p.52) - CT }\end{array}$ & \begin{tabular}{l} 
Líder em todas as pesquisas (p.60) - CT \\
\hline $\begin{array}{l}\text { Com um humor superficial facilmente azedável } \\
\text { e dona de opiniões incontrastáveis, quase } \\
\text { hieráticas (p.52) - CT }\end{array}$
\end{tabular} \\
\hline $\begin{array}{l}\text { Ela vai ter de retribuir com sorrisos artificiais } \\
\text { nos palanques os comentários mais estúpidos } \\
\text { (p.52) - CT }\end{array}$ & \\
\hline $\begin{array}{l}\text { (...) radical no discurso, mas quase sempre } \\
\text { pragmática na ação (p.54) - ST }\end{array}$ & \\
\hline $\begin{array}{l}\text { (...) desenvolveu um código de postura } \\
\text { particular. Nele, um discurso ideológico é quase } \\
\text { sempre seguido por uma decisão pragmática } \\
\text { que, não raro, acaba contrariando sua fala. (p. } \\
54) \text { - CT }\end{array}$ & \\
\hline $\begin{array}{l}\text { O figurino radical de Dilma é para petista ver. } \\
\text { O outro, norteado pela consciência de que o } \\
\text { capitalismo produz riqueza, é o que ela usa na hora } \\
\text { de pôr a mão na massa. (p.54) - CT }\end{array}$ & \\
\hline $\begin{array}{l}\text { A mudança de rota está em franca sintonia com o } \\
\text { pragmatismo à La Rousseff (p.54) - CT }\end{array}$ & \\
\hline $\begin{array}{l}\text { Dilma virou candidata graças a uma conjunção } \\
\text { de fatores. O principal deles talvez seja o } \\
\text { processo de deterioração experimentado pelo } \\
\text { PT nos últimos cinco anos. (p.58) - CT }\end{array}$ & \\
\hline $\begin{array}{l}\text { O PT, no princípio, torceu o nariz. Alegou que ela } \\
\text { era novata no partido e transformou o fato de }\end{array}$ & \\
\hline
\end{tabular}




\begin{tabular}{|l|l|l|}
\hline $\begin{array}{l}\text { Dilma nunca ter disputado uma eleição num } \\
\text { obstáculo aparentemente intransponível (p.58) - }\end{array}$ & \\
CT & \\
\hline Dois fatores foram decisivos para a virada que & \\
permitiu a aclamação de Dilma Rousseff como & \\
candidata oficial do PT. O principal é que sem & \\
nenhuma outra alternativa (..) só restou ao & \\
partido se curvar diante de Lula (p.58) - CT & \\
\hline A ministra passou de uma candidata & \\
desconhecida (...) para uma forte concorrente, & \\
com $25 \%$ marca que a coloca em segundo lugar, & \\
logo atrás do governador de São Paulo, José Serra. \\
(p.59) - CT
\end{tabular}

Após o levantamento, pode-se afirmar que a revista Veja traz um número maior de adjetivações nas edições escolhidas, 30, em relação às de CartaCapital, 25. Do total de adjetivações de Veja, 26 são referentes à Dilma Rousseff, ou seja, 86\%. Já do semanário CartaCapital, 24 são relacionadas a José Serra, ou ainda, 68\%.

Esses números demonstram que cada revista assumiu uma postura de forma a focar a cobertura pré-eleitoral em um dos pré-candidatos, $C C$ em José Serra e Veja em Dilma Rousseff. Além disso, deve-se salientar que das 17 adjetivações apresentadas em CC para José Serra, 14 são negativas, ou, $82 \%$, sendo que as ideias mais repetidas, que demonstram o enquadramento, são a queda de Serra e a sua estagnação nas pesquisas.

Já em Veja, das 26 adjetivações à Dilma Rousseff, as 26 são negativas, ou ainda, $100 \%$. As referências mais comuns são relacionadas à inexperiência eleitoral, ao pragmatismo e ao fato da pré-candidata ser uma escolha de Lula.

\section{Apontamentos finais}

Após o exame dos dados qualitativos e quantitativos, pode-se dizer que cada semanário assumiu uma postura editorial ao escolher por um determinado 
enquadramento de cada pré-candidato, visualizado na repetição de quadros discursivos. CartaCapital enquadrou José Serra negativamente e Veja enquadrou Dilma Rousseff negativamente no mesmo período.

Essa afirmação remete aos conceitos já explorados de objetividade e imparcialidade jornalísticos, que são um mito já que a atividade jornalística decorre de construções e de relatos sobre fatos que não se encontram prontos em algum lugar. A notícia só existe porque, como lembra Alsina (2009), há uma construção por parte dos jornalistas.

Então, constata-se a inexistência de tais pressupostos e o surgimento de um posicionamento editorial, proveniente da parcialidade de tais semanários. Cada revista demonstrou a sua escolha por meio dos diversos enquadramentos preferidos, manifestados em adjetivações distribuídas no espaço editorial. E mesmo que a tendência com a proximidade do pleito seja a de uma maior polarização, ela já é constatada desde o período pré-eleitoral, de forma que a opinião pública começa a ser moldada meses antes da escolha popular.

\section{Referências Bibliográficas}

ALSINA, Miquel Rodrigo. A construção da notícia. Petrópolis, RJ: Vozes, 2009.

BERGER, Christa. Do jornalismo: toda notícia que couber, o leitor apreciar e o anunciante aprovar, a gente publica. In: MOUILLAUD, Maurice; PORTO, Sérgio Dayrell (org). O jornal: da forma ao sentido. $2^{\mathrm{a}}$ ed. Brasília: Editora Universidade de Brasília, 2002.

CAMPEDELLI, Samira Yousseff; SOUZA, Jésus Barbosa. Gramática do texto, Texto da gramática. São Paulo: Saraiva, 1999.

CARTACAPITAL. São Paulo: Confiança, 2010. ed. 582.

São Paulo: Confiança, 2010. ed. 586.

São Paulo: Confiança, 2010. ed. 594.

FONSECA JÚNIOR, W. C. Análise de conteúdo. In: DUARTE, Jorge; BARROS, Antonio. Métodos e técnicas de pesquisa em comunicação. $2^{\mathrm{a}}$ Ed. São Paulo: Atlas, 2009.

GUTMANN, Juliana Freire. Quadros narrativos pautados pela mídia: framming como segundo nível de agenda-setting? Revista Contemporânea. v.4, n.1, p.25-50, 2006.

HACKETT, Robert A. Declínio de um paradigma? A parcialidade e a objetividade dos estudos dos media noticiosos. In: TRAQUINA, Nelson (org.). Jornalismo: Questões, Teorias e “Estórias". Lisboa: Vega, 1993, p.101-130.

LAGE, Nilson. Estrutura da notícia. São Paulo: Ática S.A., 1985.

, Nilson. Linguagem jornalística. São Paulo: Ática S.A., 1985. 
Estudos em Jornalismo e Mídia - Vol. $8 \mathrm{~N}^{\circ} \mathrm{I}$ - Janeiro a Junho de $20 \mathrm{I}$ ISSNe 1984-6924

MC COMBS, M. e SHAW, Donald. A função do agendamento dos media. In: TRAQUINA, Nelson. $O$ poder do jornalismo: análise e textos da teoria do agendamento. Lisboa: Minerva, 2000.

MOUILLAUD, Maurice; PORTO, Sérgio Dayrell (org). O jornal: da forma ao sentido. 2a ed. Brasília: Editora Universidade de Brasília, 2002.

PENA, Felipe. Teoria do jornalismo. São Paulo: Contexto, 2005.

TRAQUINA, Nelson (org). Jornalismo: questões, teorias e 'estórias'. Lisboa: Vega, 1993. Nelson. O estudo do jornalismo no século XX. São Leopoldo, RS: Unisinos, 2001.

2004. , Nelson. Teorias do jornalismo: por que as notícias são como são. Florianópolis: Insular,

TUCHMAN, Gaye. Contando estórias. In: TRAQUINA, Nelson (org.). Jornalismo: Questões, Teorias e “Estórias”. Lisboa: Vega, 1993, p.258 - 262.

VEJA. São Paulo: Abril, 2010. ed. 2149.

São Paulo: Abril, 2010. ed. 2153.

, São Paulo: Abril, 2010. ed. 2159. 
${ }^{\text {i } F r a m e ~ p o d e ~ s e r ~ t r a d u z i d o ~ c o m o ~ q u a d r o ~ n a r r a t i v o . ~}$

iiSalienta-se o fato de que nesta edição José Serra foi a matéria de capa.

iiiSalienta-se o fato de que nesta edição Dilma Rousseff foi matéria de capa.

iv Processo em que o presidente escolhe o candidato à sua própria sucessão.

Este artigo e todo o conteúdo da Estudos em Jornalismo e Mídia estão disponíveis em http://www.periodicos.ufsc.br/index.php/jornalismo/index

Estudos em Jornalismo e Mídia está sob a Licença Creative Commons. 